\title{
Inauguración de laboratorio de investigaciones científicas
}

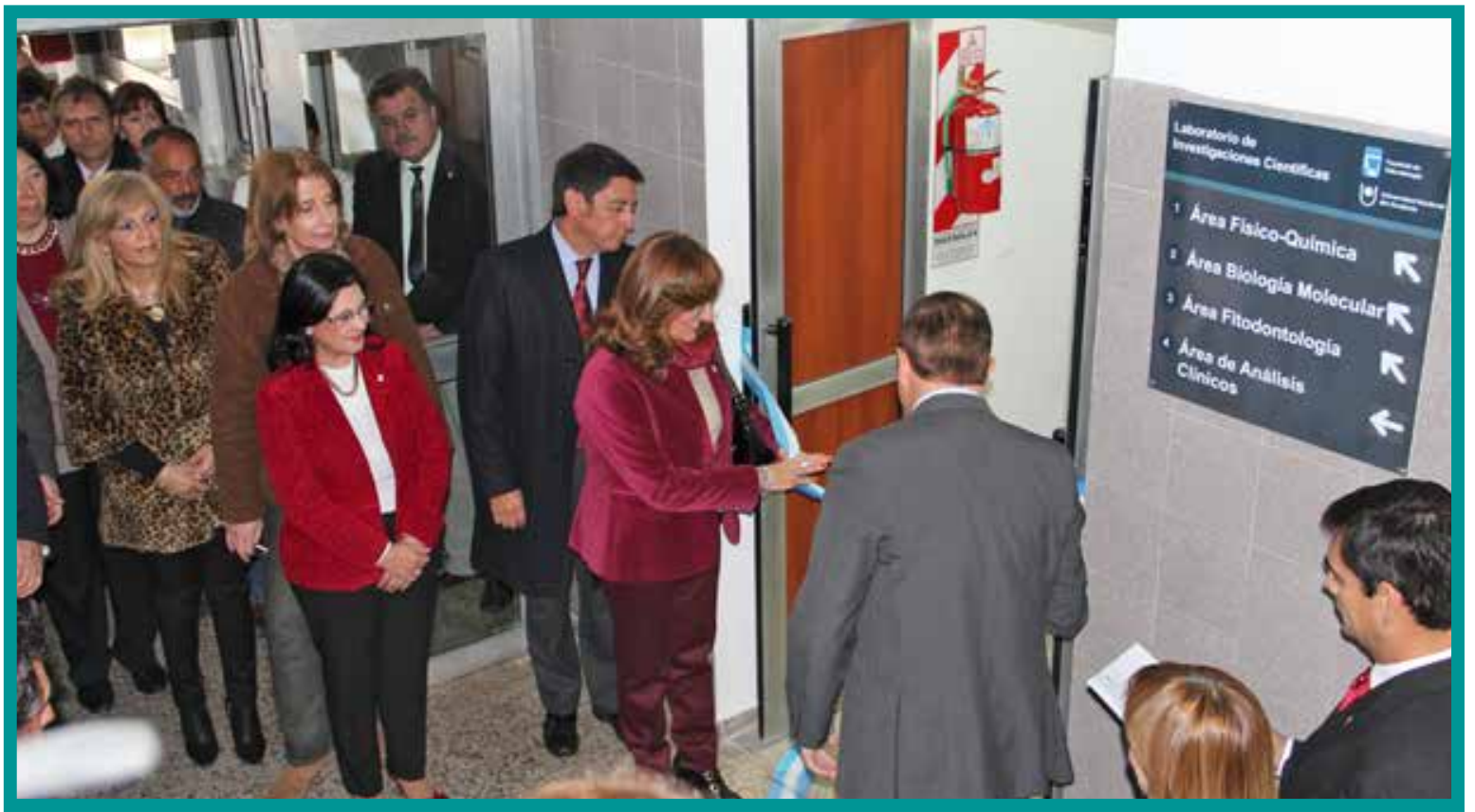

La Rectora de la UNNE inauguró el moderno Laboratorio de Investigaciones Científicas de la Facultad de Odontología, que fortalecerá las actividades de los distintos grupos de investigación.

El acto de inauguración del Laboratorio de Investigaciones Científicas contó con la presencia de la Rectora, profesora María Delfina Veiravé, el Decano de la Facultad, profesor Roque Oscar Rosende, secretarios generales de Rectorado, decanos, y demás autoridades universitarias, de las unidades académicas y de la Facultad de Odontología.

La inauguración se llevó a cabo en el marco de las "IX Jornada de Ciencia y Tecnología", "VI Jornada Nacional de Becarios y Tesistas" y "I Jornadas Internacionales" que tienen por sede la Facultad de Odontología.

"La creación del laboratorio señala un hito histórico dentro de la institución, un impulso cualitativo y cuantitativo para cada uno de nuestros investigadores" remarcó el doctor Rosende sobre la nueva infraestructura.

El Laboratorio cuenta con equipamiento de avanzada, y está organizado en Área Físico Química, Área Biología Molecular, Área Fitodontológica y Área de Análisis Clínicos.

Según explico el decano, será un espacio de respaldo a las líneas de investigación de las distintas áreas disciplinares como bioquímica, biología, microbiología, biomateriales, biología molecular, histopatología, prótesis y oclusión.

"Desde la gestión renovamos el compromiso con la investigación, a través del Plan de Desarrollo Institucional 20I4-20 I 8 que contempla un fuerte fortalecimiento en la inversión en investigación" sostuvo el profesor Rosende, y aludió a la consolidación de programas de becas, subsidios, la consolidación de grupo de trabajo e infraestructura. 
Por su parte, la Rectora de la UNNE resaltó la importancia de contar en la Facultad y en la Universidad, y en la región, con un espacio para desarrollar estudios, experiencias y desarrollo en el ámbito de la odontología.

En esa línea, durante su discurso en las jornadas de becarios e investigadores, anunció que entre las proyecciones para la misión investigación en la Universidad, justamente se prevé fortalecer la infraestructura para la investigación como respaldo a las distintas áreas y grupos científicos.
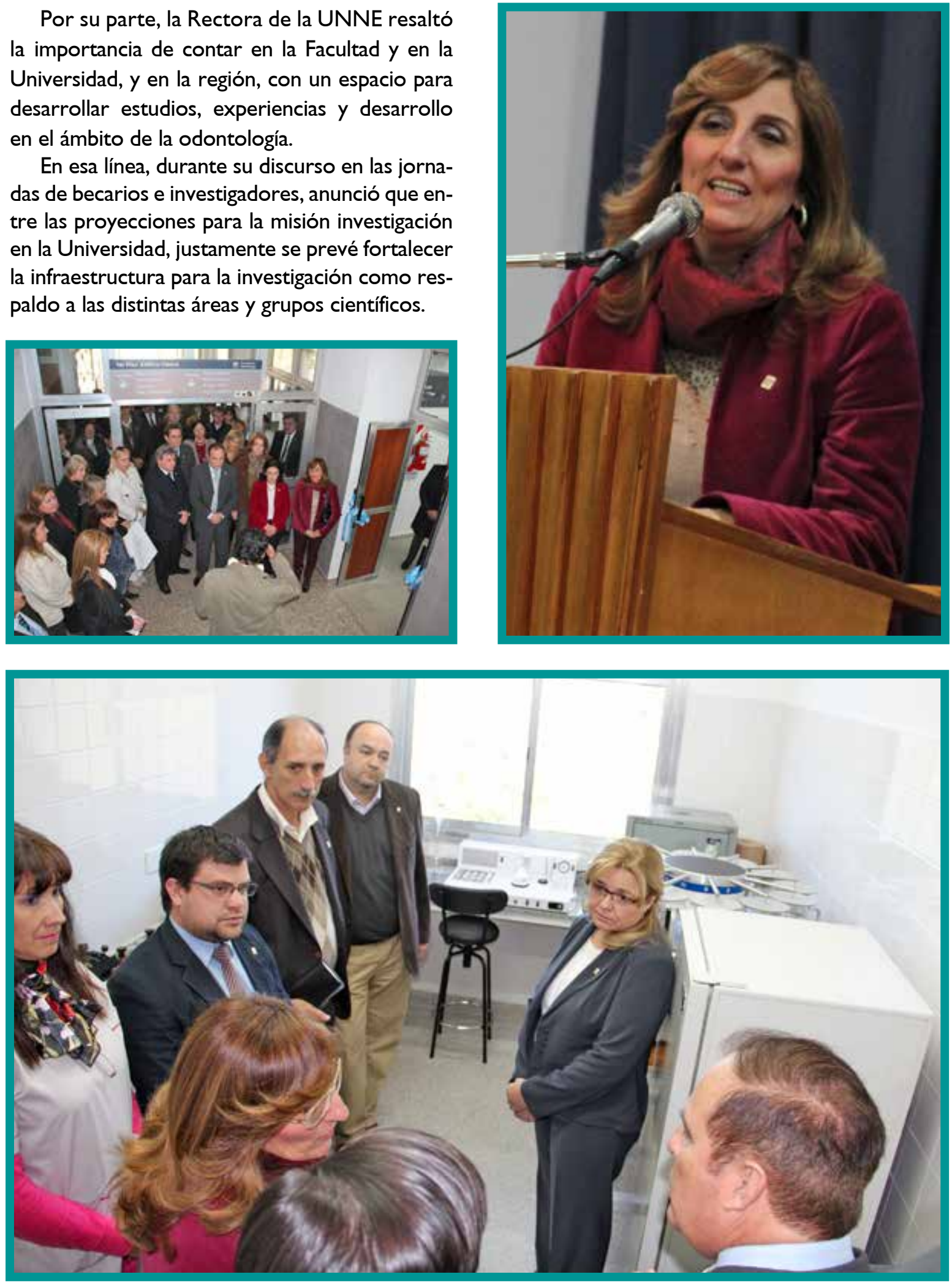